\title{
Frequency of H.Pylory BabH2 and Hpa Genes in Patients with Dysphagia
}

Khatoon Heydari (MSc)

Department of Microbiology, Islamic Azad University, Damghan Branch, Damghan, Iran Ramin Azarhoosh (PhD)

Department of Pathology, Faculty of Medicine, Golestan University of Medical Sciences, Gorgan, Iran

Vahideh Kazeminejhad (PhD)

Department of Pathology, Faculty of Medicine, Golestan University of Medical Sciences, Gorgan, Iran

Fatemeh Shakeri (MSc)

Department of Microbiology, Faculty of

Medicine, Golestan University of Medical

Sciences, Gorgan, Iran

Alireza Noroozi (PhD)

Department of Gastroenterology, 5th Azar

Hospital, Golestan University of Medical

Sciences, Gorgan, Iran

Corresponding Author: Khatoon Heydari

Email:khatunheidari@gmail.com

Address: Islamic Azad University of Damghan, Damghan, Iran

Received : 19 Mar 2013

Revised: 10 Aug 2014

Accepted: 14 Agu 2014

\begin{abstract}
Background and Objective: BabA2 and Hpa genes are involved in adherence of Helicobacter pylori (H.pylori) to gastric mucosal tissue. This study aimed to investigate the frequency of these genes in isolates of H. pylori from gastric biopsies and their relationship with gastritis, peptic ulcer and gastric cancer.

Methods: Gastric biopsy samples were obtained from patients with gastritis, peptic ulcer and gastric cancer. A sample was sent to the laboratory for urease test and histopathology study, and another sample for DNA extraction. The frequency of BabA2 and Hpa genes was investigated using their specific primers by PCR.

Results: Among the 80 analyzed biopsy samples, 51 (63\%) were BabA2 positive, and the frequency of this gene in the samples of gastric cancer, gastritis and peptic ulcer was 61.1, 50.3 and $73.3 \%$, respectively. In addition, 57 samples (71\%) were Hpa positive, and the frequency of this gene in the samples of gastric cancer, gastritis and peptic ulcer was 55.5, 69.4 and $84.6 \%$, respectively. There was no significant correlation between the presence of these genes and the type of H.pylori-related diseases.

Conclusion: Frequency of BabA2 and Hpa genes is higher in the samples of peptic ulcer but there was no significant relationship between these genes and H.pylori-related diseases.
\end{abstract}

Keywords: BabA2, Hpa, Gastric Cancer, Gastritis, Peptic Ulcer. 


\section{INTRODUCTION}

The colonization of Helicobacter pylori (H.pylori) in human stomach leads to gastrointestinal diseases such as chronic gastritis, peptic ulcer, lymphoma and gastric adenocarcinoma (1). The outer membrane proteins (OMP), glycoproteins and bacterial lipids on the surface of the bacteria are involved in communication between host cells and bacteria. Thus, the adhesins and OMP are considered as pathogenic factors. The binding factors have the most important role in inflammatory responses among all bacterial factors. H.pylori bacterium was isolated and cultured from biopsy samples of patients with chronic gastritis and cultured by Warren and Marshal in 1982.H.Pylori is one of the most common bacterial infections in the world (1). $\mathrm{BabA} 2$ protein is an important binding factor in H.pylori, which causes the binding to B-blood type Lewis antigen on the stomach epithelial cells $(2,3)$. BabA2 protein is the first $\mathrm{H}$. pylori adhesin for Lewis B antigen, identified as BabA that is of OMP origin. This adhesion existed in some $\mathrm{H}$. pyloris enables them to attach to Lewis $b$ antigen of epithelial cells. The encoding gene of this adhesion (BabA2) has two alleles (babA1 babA2), babA1 is the inactive allele and babA2 is the active form of the gene (3-5). The detection of BabA2 gene by Polymerase chain reaction (PCR) indicates the activity of this gene.Several studies on the pathogenesis of H.pylori-related diseases have demonstrated the presence of BabA2 gene and investigated the relationship between them (6). The HPa protein (H.Pylori agglutinin), one of the binding factors of H.pylori, is coded by Hpa genes and causes the binding of H.pylori to the mucosal cells of the stomach. The Hpa is the main sheath flagellar protein with $29 \mathrm{kDa}$ weight and is of H.pyloriadhesins that plays an important role in the attachment of bacteria $(7,8)$. The Hpa genes code 2 BabA proteins that facilitate bacterial virulence by increasing the production of cytotoxin and cell adhesion to the host cell.The presence of these genes have severe clinical consequences in gastroduodenal patients and brings about dyspepsia (9-11).

\section{MATERIAL AND METHODS}

This cross-sectional study was conducted on 80 patients, with gastrointestinal disorders, referring to the endoscopy unit of 5th Azar medicine ward of the hospital were undergone endoscopy according to diagnosis of gastroenterologist. A sample was taken for histopathology and urease tests and another sample was transferred into sterile vials containing saline to be used for DNA extraction and molecular methods. The urease test was performed using a kit (Baharafshan co.) and then gastric biopsy sample was sent to a pathology lab in $10 \%$ formalin. DNA extraction was performed according to the manufacturer's instructions. The extracted DNA was then stored at $-20{ }^{\circ} \mathrm{C}$ until PCR amplification. In the PCR process, a volume of $25 \mu \mathrm{l}$ containing $5 \mu \mathrm{l}$ TBE buffer, $2.5 \mathrm{ml}$ $\mathrm{MgCl}_{2}, 2 \mu \mathrm{l}$ primer (Forward and Reverse), $0.2 \mathrm{ml} \mathrm{dNTP}, 2 \mathrm{ml}$ Taq DNA polymerase and $5 \mu 1$ of extracted DNA was used for babA2 gene. For the Hpa gene, a $25 \mu 1$ volume consisting of $5 \mu \mathrm{l}$ TBE buffer, $3 \mu 1 \mathrm{MgCl}_{2}, 2$ $\mu 1$ primer (Forward and Reverse) , $3 \mu \mathrm{ldNTP}$ , $2.5 \mu \mathrm{l}$ Taq DNA polymerase and 1ul extracted DNA was used. The thermocycler temperature was programmed for the gene BabA2 as: primary denaturation temperature of $95{ }^{\circ} \mathrm{C}$ for 5 minutes and then 35 temperature cycles including: secondary denaturation temperature of $94{ }^{\circ} \mathrm{C}$ for $1 \mathrm{~min}$, Annealing temperature of $60^{\circ} \mathrm{C}$ for $1 \mathrm{~min}$ and Elongation at $72{ }^{\circ} \mathrm{C}$ for $5 \mathrm{~min}$. PCR process for the Hpa gene was programmed as the following. Primary denaturation temperature of $95^{\circ} \mathrm{C}$ for 5 minutes, 35 cycles of temperature including secondary denaturation temperature of $95{ }^{\circ} \mathrm{C}$ for $1 \mathrm{~min}$, Annealing temperature of $54{ }^{\circ} \mathrm{C}$ for 1 min and Elongation at $72{ }^{\circ} \mathrm{C}$ for $1 \mathrm{~min}$. The products of each PCR were stained with ethidium bromide in $1.5 \%$ agarose gel and then electrophoresed. Then, using a UV transilluminator and in the presence of a DNA marker (100 bpFermentase), bands were observed and compared with the marker's pattern.The voltage for electrophoresis was 70V for 40-50 minutes.

Statistical analysis:

Data were analyzed using SPSS software (version 18) and described using percentages and ratios. The chi-square test was used to compare groups and $\mathrm{P}$-value of $<0.05$ was considered as statistical significance level. 
Table1- Used primers sequences and specific markers in this study

\begin{tabular}{cl}
\hline Gene & \multicolumn{1}{c}{ Primer } \\
\hline BabA2 & F 5'-AATCC AAAAA GGA GAAAAA GTATGAAA-3' \\
& R 5'-TGTTAGTGATTTCGGTGTAGGACA-3' \\
Hpa & F 5'-ATAAAGCTT TCG GTGGTG GAACG ATG-3' \\
& R 5'-TATCTC GAGTTG TCG GTT TCT TTTGC-3' \\
\hline
\end{tabular}

Table 2- Frequency of hpa and babA2 genes in H.pylori sample The

\begin{tabular}{llll}
\hline Peptic ulcer & Gastritis & Gastric cancer & Gene \\
\hline $19(73.7 \%)$ & $21(58.3 \%)$ & $11(61.1 \%)$ & Positive babA2 \\
$7(26.9 \%)$ & $15(41.6 \%)$ & $7(38.8 \%)$ & Negative babA2 \\
26 & 36 & 18 & Total babA2 \\
$22(84.6 \%)$ & $25(69.4 \%)$ & $10(55.5 \%)$ & Positive hpa \\
$4(15.4 \%)$ & $11(30.5 \%)$ & $\mathbf{8 ( 4 4 . 4 \% )}$ & Negative hpa \\
26 & 36 & 18 & Total hpa \\
\hline
\end{tabular}

\section{RESULTS}

The presence of BabA2 and Hpa genes in the clinical samples of 80 patients with gastrointestinal disorders caused by H.pylori (18 samples of gastric cancer, 36 samples of gastritis, 26 samples of peptic ulcer) were studied and analyzed using the PCR molecular method (Table 1 and 2). The frequency of positive cases for the BabA2 and Hpa genes was 51 cases $(63.8 \%)$ and 57 cases $(71.2 \%)$, respectively. In this study, the frequency of positive BabA2 and Hpa genes in peptic ulcer patients was higher than patients with gastritis and gastric cancer. However, there was no significant relationship observerd between $\mathrm{Hpa}$ and BabA2 genes in gastric cancer, peptic ulcers and gastritis $(\mathrm{P}$-value $>0.05)$.

\section{DISCUSSION}

Binding of H.pylori to gastric mucous and epithelial cells is an important step in the pathogenesis of this bacterium. Following the binding of H.pylori to the mucosal surfaces of the gastrointestinal tract, the host tissue become exposed to the bacterial enterotoxin. Adhesins, proteins, glycoconjugates and bacterial lipids are involved in the early stages of bacterial colonization $(3,12)$. In Shirazi et al. study which was conducted in Tehran, although BabA2 gene frequency in gastric cancer samples was higher than other gastrointestinal diseases, no significant relationship was observed between this gene and gastric cancer (3). The inconsistency between their findings and this study could be due to geographical and genetic diversity. In this study, the frequency of OMP of $\mathrm{H}$. Pylori and their adhesion ability were studied. BabA2 protein is functionally active and can bind to blood group antigens (6,7). Ishaqi et al. reported no significant relationship between BabA2 genotype, gastritis and peptic ulcer but BabA2 association with gastric cancer was observed. Whereas in our study, no significant association was found between the presence of BabA2 gene, gastric cancer, peptic ulcer and gastritis. Although a large number of articles has indicated the association of BabA2 gene with various $H$.pylori-related diseases (6), this study similar to some others, observed no significant relationship. In Ghasemian, Safaee and colleagues study in 1387, the frequency of BabA2 gene in 81 patients with gastritis, peptic ulcer and gastric cancer was reported as $68.2,74.1$ and $80 \%$, respectively while the overall frequency of BabA2 gene was $71.6 \%$ (7). Hpa protein is another H.pylori OMP which is involved in binding and adhesion of H.Pylori to the gastric mucosa, as well as providing the opportunity for gastrointestinal inflammation (10). In a study conducted in the U.S by Carlson, Hpa gene frequency in gastritis, duodenal ulcer and gastric cancer patients was reported as $66 \%, 44 \%$ and $70 \%$, 
respectively. However, no significant association was reported between the presence of HPa and gastric cancer (13).

\section{CONCLUSION}

The most $\mathrm{H}$. pylori strains have these genes which increase the incidence of peptic ulcer in patients, harboring the bacteria and also increase the risk of other diseases such as gastritis and gastric cancer. BabA2 and $\mathrm{Hpa}$ genes were more frequent in patients with peptic ulcer and less frequent in

\section{REFERENCES}

1. Shokouhizadeh L, Mohabati Mobarez A, Sadeghizadeh M, Amini Mohsen. Evaluation of Helicobater Pylori Caga Gene Relationship And Endoscopic Findings. Kowsar Medical Journal. 2006; 11(3): 261-266.

2.Mobaraki R. Detection of Helicobacter pylori cagA gene and genotypes vacA in patients suffering from digestive disorders with Multiplex PCR method. Iranian Biologhy Journal. 2012; 6.

3. Shirazi M, Pazbaz Z, Douraghi M. Frequency of babA $_{2}$ Genotype in Helicobacter pylori From Patient Gastruodenal Diseases in Firoozgar Hospital in Tehran. Gastrointestinal. 2012; 17(2):78-83.[Persian]

4. Erzin Y, Koksal V, Altun S, Dobrucali A, Aslan M, Erdamar S, et al. Prevalence of Helicobacter pylori vacA, cage, iceA, BabA2 genotypes and correlation with clinical outcome in Turkish patients with dyspepsia. Helicobacter. 2006; 11(6): 574-80.

5. Karima TM, Bukhari SZ, Ghais MA, Fatani MI, Hussain WM. Prevalence of Helicobacter pylori infection in patients with peptic ulcer diseases. Saudi Med J. 2006; 27(5): 621-6.

6. Eshaghi $M$, Ghasemian Safaei $H$, Havaei AA, Navabakbar F, Salehi R, Tavakoli H, et al. Frequency of BabA2 genotype of H.pylori and relation with gastroduodenal disease 2009. Scientific Journal of Kurdistan University of Medical Sciences. 2008; 13(3): 22-29. patients with gastric cancer compared with other diseases.

\section{ACKNOWLEDGMENT}

I would like to thank Ms.Taghavi, our colleague in the pathology and endoscopy unit of 5th Azar Hospital, for providing us with the biopsy samples and Ms.Fatemeh Shakeri, staff of Microbiology unit of Golestan University of Medical Sciences.

\section{CONFLICT OF INTEREST}

There are no conflicts of interest.

7. Ghasemian Safaei H, Havaei AA, Tavakoli H, Eshaghi M, Navabakbar F, Salehi R. Relation of bab A2 genotype of helicobacter pylori infection with chronic active gastritis, duodenal ulcer and non-cardia gastritis in Alzahra hospital Isfahan. JJM. 2010; 3(3): 93-98.

8. Bittencourt PFS, Rocha GA, Penna FJ, Queiroz DMM. Gas troduodenal peptic ulcer and Helicobacter pylori infection in children and adolescents. J Pediatr (Rio J). 2006; 82(5): 325-34.

9. Hessey SJ, Spencer J, Wyatt JI, Sobala G, Rathbone $\mathrm{BG}$, Axon AT, et al. Bacterial adhesion and disease activity in Helicobacter-associated chronic gastritis. Gut. 1990; 31(2): 134-8.

10. Logan RP. Adherence of Helicobacter pylori. Aliment pharmacol Ther. 1996; 10: 3-15.

11. Mizushima T, Sugiyama T, Komatsu Y, Ishizuka J, Kato M, Asaka M. Clinical relevance of the BabA2 genotype of Helicobacter pylori in Japanese clinical isolates. J Clin Microbiol. 2001; 39(7): 2463-5.

12. Abdollahi H, Shokoohi M, Savari M. The prevalence of Helicobacter pylori babA2, ice A2 Genes and their Association with clinical out comes in Pathients with chronic Gastritis ulcerative Diseases and Nonulcer Dyspepsia in south East of Iran. Jundishapur Journal of Mirobiology. 2013; 6(4): e4739.

13. Carlsohn E, Nyström J, Bölin I, Nilsson CL, Svennerholm AM. HpaA is essential for Helicobacter pylori colonization in mice. Infect Immun. 2006; 74(2): 920-6. 